\title{
Filosofia da educação e pensamento das multiplicidades em Michel Serres
}

\section{Maria Emanuela Esteves Santos ${ }^{1}$}

\section{Resumo}

O objetivo desse trabalho é trazer uma abordagem das multiplicidades como teoria da comunicação, segundo o pensamento de Michel Serres, e suas possíveis contribuições para se pensar um projeto de filosofia da educação como 'a'fundamento da educação. Trata-se de 'a'fundamento da educação, visto que essa filosofia tensiona sobre os clássicos pares sujeito-objeto, conhecimento-ação. Tal projeto de filosofia da educação, por sua vez, estaria em melhor consonância aos desafios contemporâneos da educação que a filosofia de Michel Serres reconhece naquilo que denomina população Polegarzinha, que demonstra a necessidade cada vez mais presente de uma educação como relação na diferença.

Palavras-chave: Multiplicidades; Filosofia da educação; Michel Serres.

\section{Résumé}

Cet article cherche démontrer de quelle façon la philosophie de Michel Serres se constitue-t-elle en approche substantive des multiplicités, qui permet penser un projet de philosophie de l'éducation comme 'a'fondement de l'éducation. Il s'agit d' 'a'fondement de l'éducation car cette philosophie met en tension les paires classiques sujet-objet et connaissance-action. Un tel projet de philosophie de l'éducation aurait une meilleure consonnance avec les défis contemporains de l'éducation que la philosophie de Michel Serres reconnaît dans la population Petite Poucette et qui démontre un besoin toujours plus présent d'une éducation comme relation dans la différence.

Mots-clé: Multiplicités; Philosophie de l'éducation; Michel Serres.

\footnotetext{
${ }^{1}$ Graduada em Pedagogia pela Universidade Federal de São João del Rei (UFSJ, 2006),
} mestra e doutora em Educação pela Universidade Estadual de Campinas (2010/2016). 


\section{Introdução}

relevante trazermos as muitas e significativas contribuições do
pensamento de Michel Serres para a educação, visto que é vasto o
campo de extensão e correspondências de suas reflexões sobre temáticas as mais diversas: política, economia, ecologia, cultura, ou, até mesmo, questões mais cotidianas e corriqueiras do dia a dia, que não se ligam diretamente a nenhum campo hermético e estruturado de conhecimento. Entretanto, em meio a esse cenário diverso, destaca-se, pela preponderância e pelo alcance das reflexões, o problema ou as questões da educação e, sobretudo, da educação contemporânea, às quais Serres se dedicou nos últimos tempos. Alcance esse, por sua vez, que pode ser melhor compreendido quando abordado a partir dos principais conceitos que caracterizam o que denominamos pensamento das multiplicidades em Michel Serres.

A convergência desses conceitos, portanto, nos ajudará a pensar de que forma a filosofia de Serres e seus personagens/mônadas podem nos ajudar a configurar um projeto de filosofia da educação, que, longe de se colocar como fundamento da educação, é capaz de nos levar à perspectiva do 'a'fundamento da educação, no nosso entendimento, bem mais propícia aos desafios educacionais hoje, como tentaremos demonstrar.

\section{1 - Pensamento das multiplicidades em Michel Serres}

Segundo Serres, a diferença principal entre Descartes e Leibniz consiste no fato de que o primeiro exclui a mistura e o segundo simplesmente a decompõe. Ao proceder dessa forma, Leibniz se torna bem mais interessante para Serres do que Descartes quando se consideram essas duas principais vertentes do pensamento clássico. Assim, na contramão da inspiração predominante do pensamento racional tradicionalista, Serres vai buscar em Leibniz ver o que resta ao fundo. Não basta apenas destacar o objeto, livrálo de todo o meandro de confusão e desordem, cercá-lo de métodos e procedimentos que sejam capazes de vê-lo em sua pureza, expurgar toda a 
mistura que pudesse confundir as suas propriedades, retirar o fundo caótico de onde ele está. Para Serres, ao contrário, o que importa é a pergunta: mas o que resta ao fundo?

De acordo com o racionalismo tradicional, da mesma forma que "Deus filtra os possíveis pro gradu essentiae, ou que hierarquiza os seres pro gradu perfectionis, com a mesma lógica, o homem filtra, classifica e ordena as ideias pro gradu distinctionis, separando, por etapas, o verdadeiro do falso e o falso do verdadeiro" (SERRES, 1968, p.130, grifos no original). O conceito misturado é eliminado "pela razão completamente simples de que o falso não teria, em proporção, uma medida comum com o verdadeiro: o aparentemente verdadeiro é falso por uma impensável composição" (p.130-131). Por outro lado, Leibniz, longe de eliminar as misturas - afinal, nada mais há que misturas -, busca pensar uma série de provas para avaliar os conteúdos que se apresentam na mistura entre falso e verdadeiro, de modo semelhante com que se avalia "no verde a quantidade de amarelo e de azul que lhe compõem" (p.131). O que temos, então, é um processo de explicação: "o falso é talvez o complicado do implicado, a sombra quase interior da conjunção combinatória, a complexidade da complexão, a dificuldade cruzada do recobrimento" (ibidem). É dessa maneira que, na medida em que a análise e a decomposição progridem, e que se procede à triagem, o complexo se reduz ou se afasta. "Se há natureza simples, ela não aparece a não ser como extrato do complicado. Tudo se combina para o cálculo de aproximações: decomposição analítica, separações inteiradas, seguimentos finitos e infinitos que aproximam o racional do irracional" (SERRES, 1968, p.132, grifo no original). E nesse processo, o aparentemente verdadeiro, antes excluído, se decompõe, pois, em aparente e verdadeiro.

Por essa razão, Leibniz - e assim também Serres - se recusa a repudiar $o$ fato, a coisa ou o acontecimento, em nome de um processo totalmente centrado e regrado por normas rígidas, uma vez que essa ação consistiria em se privar dos benefícios da invenção em prol de uma “segurança integral e primeira que ele reconhece desejável, como aqui, mas 
impossível ou fictícia" (SERRES, 1968, p.136). Isso porque o fato sempre se compõe simultaneamente do um e do seu inverso, o primitivo e o derivativo e as relações que os unem, composição-decomposição, combinatória-análise. "Há uma composição de cores, de verdades, de noções e de números, de signos ou de caracteres, de letras e de palavras, de movimentos enfim" (p.138). E nessa composição infinita, cabe-nos promover complicações cada vez mais crescentes para gerir proposições, definições, até mesmo teorias e disciplinas científicas. Promover relações, passar por entre os domínios, cruzar, compor e dessa composição ver surgir o novo. Nisso consiste criar, nisso consiste a tarefa do filósofo - ou ao menos, nesse caso -, a tarefa e o objetivo do filósofo Serres. Em Le gaucher boiteux (2015), logo na primeira página, o filósofo afirma: "pensar quer dizer inventar. Todo o resto - citações, notas em pé de página, índice, referências, copiar-colar, bibliografia de pesquisas, comentários... - pode passar por preparação, mas cai muito rapidamente em repetição, plágio e servidão" (p.5). Portanto, o movimento consiste em: "imitar sim, de início, para se formar, nada há de desonroso nisso, é preciso aprender bem. Mas em seguida é melhor esquecer essa grade de ferro, esse formato, para levemente inovar" (ibidem).

Para que aconteçam os dois momentos desse processo, é preciso que o primeiro, o aprender, segundo Serres (2015), se constitua a partir da consideração de que "uma tal ciência estrutural enuncia in universo leis formais advindas de constituições locais" (ibidem, grifo no original). Isso porque, na distância entre universal e primitivo, o último se coloca como núcleo constitutivo de cada região e o primeiro determina a teoria geral de toda constituição. Logo, "o universal compreende o primitivo, como uma língua compreende uma palavra, como uma ciência compreende uma de suas disciplinas" (p.139). E, por conseguinte, "se cada região compreende o primitivo como princípio ou requisito, o universal o compreende como objeto ou parte" (ibidem). Em razão disso, "é menos interessante considerar sua primitividade que sua generalidade, é menos fecundo sublinhar a generalidade do primitivo que sua eficácia na constituição" (ibidem, grifo no 
original). Dessa forma, a filosofia de Serres não busca diluir a singularidade na generalidade, destacando a diferença como parte da unidade. Na verdade, ela busca reforçar a fecundidade dessas singularidades quando relacionadas e compondo uma generalidade qualquer. E nesse ponto se dá a passagem extremamente rápida do aprender à invenção. Quanto maior o número de entrecruzamentos, mais diversas e ricas são as composições. E, para estarem juntas, para comporem essa generalidade, há a necessidade da harmonia que une, aproxima e faz surgir o novo composto. Contudo, trata-se de uma harmonia aberta, pois os entrecruzamentos podem ser infinitos a cada novo rearranjo do sistema pela incidência constante de novas séries convergentes e divergentes nesse espaço. O movimento, pois, da aprendizagem à invenção permanece aberto. Arlequim não cessa de atravessar o rio, nem de despir suas vestes.

Assim, por inspiração leibniziana, Serres se constitui como um filósofo da composição ou da comunicação, que devem ser compreendidas, nesse caso, como a busca em promover deslocamentos, construir pontes entre os saberes, compondo, colocando em contato, fazendo comunicar, por meio desses entrecruzamentos, novos saberes, o que só será possível tendo por horizonte a compreensão de que a diferença e a multiplicidade são os elementos em princípio. Por isso, são necessários uma art des ponts e seu homo pontifex. Mas, para Serres, não basta apenas considerar as multiplicidades e a diferença em princípio, é preciso ver essas diferenças em composições constantes, em correspondências ou comunicação. Ver o cromatismo se formando pela junção de diferentes cores no casaco de Arlequim e ver ainda como essas cores juntas, em interseção de séries, podem criar uma nova harmonia temporária no branco alvo de Pierrot, a soma de todas as cores. É fundamental, portanto, promover passagens, juntar os disparates, não para contê-los em uma unidade, mas para vê-los juntos formarem algo novo e temporário, até que novos entrecruzamentos venham atravessá-los, seguindo, assim, o movimento proposto de uma Filosofia mestiça. 
Isso porque, para Serres (1968), a pura multiplicidade pode ser designada "em termos de mistura aleatória, de complexão em geral [...] de seguimento aritmético ou conjunto de números, de recobrimentos criptográfico ou algébrico" (p.145). Ou seja, é possível tratarmos a multiplicidade como uma variação contínua que "percorre o seguimento semântico da complicação à implicação". Esse movimento contínuo da complicação à implicação é muito próximo, a nosso ver, do movimento proposto por Deleuze do atual ao virtual. Aqui, na terminologia de Serres, o movimento é tratado do complicado presente, que tensiona continuamente sobre o implicado, por ora desenvolvido. Mas esse movimento não para por aqui. É necessário, ainda, avançarmos para o aplicado, espaço onde acontecem as relações dos elementos complicados/implicados. Afinal, nesse espaço, tudo converge, conspira, consente. Temos, pois, em Serres, um movimento que parte da complicação, passa pela implicação e chega à aplicação. E é no sentido desse último movimento, sobretudo, que consideramos esteja a sua principal contribuição para um pensamento das multiplicidades.

No âmbito da relação na diferença, os personagens na filosofia de Serres - os quais podem ser, por sua vez, compreendidos como personagens/mônada em correspondência à filosofia leibniziana -, são singularidades, mas são, também, todos os outros possíveis, isto é, uma universalidade. E assim o são pelo movimento contínuo do complicado ao implicado, ou do atual ao virtual, rumo ao aplicado. Por essa razão, mais uma vez, Serres se interessa por Leibniz na contramão de Descartes, pois a ele interessa essa mistura complicado/implicado, esse impuro, esse complexo que é preciso decompor e levar à aplicação, sem que seja desconsiderado ou desligado, o fundo caótico de onde todas as coisas partem e onde todas as coisas tensionam. É dessa forma também que, considerando a passagem do singular ao universal, todos exprimem um e um exprime todos (SERRES, 1968), observando que não se trata de uma redução de todos no um, pelo duplo movimento evocado, mas de uma consideração que reafirma que o um, singularidade, traz em si todos - 
universalidade. Essa complicação/implicação é que permite, afinal, a comunicação ou a aplicação entre as diferenças. Assim, cada personagem/mônada traz em si um implicado desenvolvido que lhe pertence e que define a sua singularidade, mas, ao mesmo tempo, carrega consigo todos os outros possíveis complicados nesse fundo obscuro e que the permitem a comunicação com os outros, que também são singularidades pelos implicados específicos que desenvolvem e aos quais correspondem os complicados do meu fundo obscuro. É por isso que o confuso é uma perspectiva do distinto, uma anamorfose, na qual a desfiguração pode levar à dessemelhança, a alteridade pode esconder alguma similitude (Serres, 1968). Nesse sentido, o corte cartesiano do claro e do confuso é preenchido pela continuidade expressiva de Leibniz (ibidem). Isso interessa a Serres, uma vez que ele busca: quais as possíveis relações que podem acontecer na diferença? É preciso, para tanto, constituir alguma correspondência, alguma ligação entre as multiplicidades que levem a compor o novo; engendramento de alteridades por múltiplas relações; as múltiplas performances de Hermes a buscar passagens.

Outra implicação da continuidade expressiva de Leibniz incide sobre a concepção de variações de pontos de vistas de Serres. Se cada personagem/mônada implica um mundo específico e complica todos os outros, possíveis e impossíveis, é fato, então, que essa mônada só implica claramente uma parte desse mundo e que as demais estão complicadas em uma zona obscura. Para chegarmos a um determinado conhecimento, portanto, é necessário aproximar cada ponto de vista a partir do máximo de relações possíveis, implicação clara do mundo, dos personagens mônadas. Quanto mais aproximações e relações fizermos, maior a expressão ou implicação do mundo tecida nesses agenciamentos. A aplicação, assim, torna-se forma de nos aproximarmos da complexidade do mundo por meio das implicações de cada mônada, a qual corresponde um ponto de vista. Contudo, esse ponto de vista, o implicado claro da mônada, não pode ser considerado sem o seu tensionador contínuo, ou seja, o complicado escuro. A zona clara da implicação do mundo no personagem/mônada não está 
desassociada ou deslocada da sua zona escura de complicação. Essa zona atua diretamente e incide sobre a zona clara, tensionando continuamente. Para compreender melhor essa relação do perspectivismo com a zona obscura, Serres (1968) nos remete à relação que existe na geometria e, também, em outras disciplinas que trabalham com a ideia de projeção, da influência de uma teoria das sombras sobre a perspectiva. "A doutrina das sombras nada mais é que uma perspectiva revertida e resultante dela mesma, quando colocamos o luminoso no lugar do ponto de vista, o opaco no lugar do objeto e a sombra no lugar da projeção" (p.165). Nesse caso, temos a perspectiva, porém esta não pode ser desassociada do seu inverso, uma teoria das sombras. Não podemos falar de ponto de vista sem considerarmos a sombra que resta sobre o objeto ou mundo ao tomarmos tal ponto ou tal ângulo para nos estabelecermos. É dessa forma que o perspectivismo em Leibniz, como considerado por Serres, não pode se estabelecer totalmente num ponto de vista específico e estável, pois ele é tensionado a todo momento por essa sombra que a projeção produz.

Logo, por não ser estável, o ponto de vista aqui está muito mais próximo da proposta de "vistas sem pontos" que a filosofia de Deleuze (2012) propõe para uma superação das limitações do pensamento leibniziano quanto de uma teoria das multiplicidades. "Entre as invenções que associam perspectiva e teoria das sombras, é preciso considerar como decisiva aquela que faz passar do discreto ao intensivo, da figura ao fundo, do confuso ao distinto" (SERRES, 1968, p.170). Isso porque "reverter os dados faz voltar a completar os resultados: completar, ou seja, passar do distinto ao contínuo da aritmética à análise, do gráfico de perspectiva à topografia, às sombras graduadas" (p.171). Assim, tudo se passa como se "a exploração de um contínuo devesse requerer as condições inversas àquelas que regem o colocar-se em evidência de um elemento que se destaca distintamente sobre esse fundo" (ibidem). O perspectivismo que leva à relação um-todos ou mesmo um-infinito constitui, pois, "uma relação que permite mergulhar um dado ser em uma multiplicidade da qual ele resulta, o gráfico no alívio topográfico, a curva na família das tangentes, o número 
inteiro na densidade dos racionais" (p.171-172). Afinal, sempre "há mil e uma maneiras de completar o mundo, de preencher as lacunas, de recusar o vazio" (p.172, grifo no original).

É preciso dizer que o inverso aqui não significa o oposto, o contrário, o contraditório, mas sim "o máximo de alteridade compossível com a identidade" (Serres, 1968, grifo no original). E é nessa perspectiva que a harmonia se instaura: "quando intervém uma combinação fina entre o um e o diverso, na qual significa que o outro se diferencia às vezes e se combina com o mesmo e que, no limite, existe na família dos outros elementos de alteridade máxima" (ibidem). O inverso é posto assim como o máximo de diferença compossível ainda em relação à identidade, e é esse máximo de diferença compossível que vai tensionar sobre a identidade, fazendo-a variar e levando-a aos limites do incompossível. Trata-se, pois, de uma diferença causal máximo-mínimo, como nos casos claro e escuro, contínuo e discreto, infinito e finito, universal e particular, num processo em que o mundo do diverso é engendrado ao mesmo tempo em que engendramos o mundo do um. E quando combinamos esses dois processos, engendramos, por sua vez, o mundo harmônico (SERRES, 1968).

Nesse sentido, todo ato de conhecimento consiste em "tirar $o$ verdadeiro de seu falso" (SERRES, 1968, p.178, grifo no original), como também consiste em "descobrir o falso residual desse verdadeiro temporário" (ibidem, grifo no original). Logo, o ato do conhecimento consiste em um movimento que vai "do verdadeiro de seu falso ao falso de seu verdadeiro e assim sucessivamente" (ibidem), o que equivale ao movimento de clarear a zona sombria, bem como assombrar a zona clara. Em outras palavras, trata-se de "colocar um filtro progressivo (serial) cada vez mais refinado sobre o filtro global e grosseiro do verdadeiro e do falso em geral que separa a mistura originária" (ibidem, grifo no original), donde, então, a dupla variação de situs no processo de conhecimento, a qual vibra entre as instâncias, ora regiões claras, ora obscuridade e uma agindo sobre a outra continuamente. Nesse processo de dupla variação de situs: o obscuro clareia-se, mas esse claro é confuso; o confuso se distingue, mas esse 
distinto é inadequado; em seguida, o adequado é cego, é aqui, então, que a sombra é expulsa pelo pensamento intuitivo, momento único em que soa a hora do meio dia (SERRES, 1968). A dupla variação de situs tensiona, pois, entre esses dois estados inversos para culminar, enfim, na intuição: único momento em que se dissipa toda a sombra, pelo advento temporário e fugaz do sol pleno naquele instante.

Por essa razão, não nos interessa um cogito, único, estável, bem determinado como proposto por Descartes. Interessa, sim, essa complexidade misturada, esse impuro e indeterminado, esse confuso, que não nos traz segurança nem estabilidade, entretanto, é capaz de acompanhar a intensidade da vida e das coisas em sua realidade variável e variante. Logo, o personagem/mônada de Serres sempre traz algo de Arlequim, personagem das multiplicidades infinitas, variedade confusa de cogitata, mar ou rio de pequenas percepções, inclinações e dores imperceptíveis ou máquina infinita da natureza, desenvolvendo e recobrindo germes. "Arlequim reaparece, não mais indiferente aos outros mundos monótonos, mas se despindo sem fim sobre o próximo teatro, no desespero de nunca chegar ao seu último traje" (SERRES, 1968, p.184). Na mistura, a variação se torna, pois, variação contínua e engendramento de multiplicidades por interseção de séries.

Não podemos desconsiderar, é fato, que Leibniz representa a realização de um certo classicismo de inspiração cartesiana, bem provavelmente o seu coroamento e sua verdade. Contudo, de acordo com Serres (1968), na mesma proporção, o pensamento de Leibniz contém, também, o conjunto de críticas que podemos fazer ao cartesianismo e que podem culminar no seu fim ou na sua morte. Instalação das fundações: Le parasite; Genèse; Détachement; Rome; Statues. Isso acontece porque o ideal gnosiológico e metodológico que o classicismo atribui à palavra certeza, Leibniz atribui à palavra estabelecimento. Para o primeiro, não importa o caminho acumulativo da invenção, da descoberta, do inventário enciclopédico, mas "a circunscrição crítica dos seus índices de segurança" (p.215, grifo no original). Não importam a riqueza e o movimento do 
processo, mas "a regressão questionadora em direção a um ponto fechado" (ibidem). Por conseguinte, "no limite, a maior certeza é o zero do conhecimento, o cogito" (ibidem, grifo no original). À circunscrição cartesiana, Leibniz propõe o dinamismo inventivo implicado no termo estabelecimento. Ao propor esse termo, Leibniz permanece clássico, uma vez que, por ele, a princípio, evocamos um método capaz de fornecer "índices efetivos de certeza, marcas objetivas de segurança” (p.216, grifo no original). $\mathrm{O}$ que equivale dizermos que "se impõe a um organon metódico que ele seja um organon de verdade" (ibidem, grifos no original). A questão é que Leibniz não para por aí. Ele vai mais longe. Estabelecer é, sim, de fato, "assegurar-se, colocar fora de disputa, fechar uma discussão" (ibidem) para chegar a uma outra dificuldade: estabelecer não é mais retornar sobre um ponto, mas, sim, poder continuar sem jamais ter de se preocupar com o estabelecido (ibidem). É assim que o método de verdade se torna em Leibniz uma arte de inventar, É por esse processo que ele equilibra "um método de certeza e uma ars inveniendi" (p.216, grifo no original).

Observamos, assim, mais uma vez, a defesa que Serres faz da filosofia de Leibniz como um pensamento criativo. Ao compreender a obra leibniziana em uma perspectiva aberta, sem as concentrações definitivas no âmbito da mônada e do mundo, Serres consegue dar vez para a dimensão criativa do pensamento e da práxis leibnizianas, considerando não só as orientações de sua filosofia, mas, sobretudo, a forma como ele promoveu passagens e combinações numerosas e criativas nos diversos domínios sobre os quais ele escreveu. Para Serres (1968), o método de Leibniz, ao entrelaçar certeza e invenção, acaba por "abrir o racionalismo clássico, recusando se fechar nos requisitos de segurança e miragens de um fundamento in subjecto para caminhar alegremente, compensando a desconfiança duvidosa por um dinamismo confiante no progresso espiritual" (p.216-217, grifo no original). O estabelecimento, trata, portanto, de uma "equilibração fina entre as diversas estruturas de fechamento, de término, de circunscrição e as estruturas outras de abertura, de acabamento indefinido, de acumulação" (p.217, grifo no original). E é assim, por sua 
vez, que a harmonia se compõe: por meio de estabelecimentos variados quando acontece a convergência das séries em equilibração, tensionadas, porém, pelas estruturas outras de abertura e acabamento indefinido. Logo, uma harmonia aberta por estabelecimentos, ou equilíbrios contínuos entre progressões e estabilidades. Assim, que o personagem/mônada possa avançar sem travas, salvo o tempo do sono, do sonho e dos esquecimentos, do obscuro em direção ao claro, do confuso em direção ao distinto. Que ele possa se libertar das sombras, indefinidamente desdobrando isso que é nele e em todos os lugares, o falso, replicado infinitamente. $\mathrm{O}$ personagem/mônada faz um esforço contínuo em direção ao conhecimento lúcido, transparente, na tentativa de construir um mundo menos sombrio e mais luminoso a partir desse esforço (Serres, 1968).

É por essa razão que Serres elege o pluralista Leibniz em vez do dogmático Descartes, pois é essa mistura, esse complexo, esse olhar para o impuro que ele busca em sua própria filosofia. Ambientados ambos na matemática e buscando suas implicações para o pensamento filosófico, em Descartes o método vai "aderir a um modelo único de álgebra (ou de geometria algébrica)" (SERRES, 1968, p.219). Leibniz, por sua vez, "desata essa aderência e suprime essa eleição. Ele faz proliferar vagarosamente os modelos matemáticos, nos quais nenhum julga os outros, mas cada um verifica os outros e garante sua eficiência" (ibidem). Com isso, ele faz emergir a flexibilidade do método, "a variação incessante e regrada da região linguística e lógica, a surpreendente complexidade de ligações que faz corresponder o problema e suas referências rigorosas e essas últimas entre elas" (ibidem). Portanto, de Descartes a Leibniz, "se passa da unicidade de aderência à pluralidade de correspondências" (ibidem, grifo no original).

Na pluralidade de correspondências, nada é centrado, ao contrário do que acontece no espaço de coordenadas cartesianas. O centro está em toda parte e a circunferência em nenhuma. $\mathrm{O}$ personagem/mônada, como ponto de harmonia das séries convergentes e divergentes, não é, portanto, ponto fixo e referencial estável. Ele é centro relativo para todos os lados, uma vez

Filosofia e Educação [RFE] - Volume 9, Número 2 - Campinas, SP Junho-Setembro de 2017 - ISSN 1984-9605 - p. 98-124 
que o que ele está em variação contínua pela interseção de séries. Assim, no espaço descentrado leibniziano do personagem/mônada, "todo elemento é, alternadamente, polo e margem, centro e borda, invariante e variável, ponto de vista e coisa vista, sujeito e objeto" (Serres, 1968, p.436). Nesse espaço multipolar e relativista, o sistema leibniziano consiste em um sistema "representável por um imenso determinismo onde cada tema é associado a todos os outros e onde todos os temas são uma complexão de cada um" (p.437, grifo no original).

No âmbito da mônada e do mundo, essa continuidade de correspondências também repercute entre o que a mônada é - sujeito ou suporte pontual de uma multiplicidade contínua de relações - e seu inverso - objeto do mundo que se constitui nela e por ela. Da mesma forma, o mundo é objeto, como expressão na mônada, e ao mesmo tempo, sujeito que constitui por si mesmo, ao recompor a multiplicidade de expressões de todas as mônadas. Logo, “o sujeito é ao mesmo tempo sujeito e objeto. O objeto é ao mesmo tempo objeto e sujeito" (SERRES, 1968, p.389, grifo no original). $\mathrm{Ou}$, em outras palavras, "eu compreendo nele o mundo que o compreende como elemento" (ibidem, grifo no original), ou verte-se ele em torno do mundo que, por sua vez, verte-se reciprocamente em torno dele. Desfaz-se com isso uma possível supremacia do personagem/mônada que poderia seguir submetendo o mundo aos seus esquemas de compreensão e apreensão da realidade como um sujeito do conhecimento. Na verdade, a continuidade entre algo e seu inverso traz para essa dimensão a mútua implicação: sujeito, mas, ao mesmo tempo, objeto; objeto, mas, ao mesmo tempo, sujeito. Essa mútua implicação será um dos elementos mais característicos da filosofia de Serres, à qual ele estenderá suas reflexões, dando novos contornos específicos de aplicação, sobretudo, nas reflexões que empreende para os problemas ambientais. Muitos desses problemas ambientais de hoje são analisados por Serres como consequentes da perspectiva que relega o mundo ao simples posto de objeto sobre o qual incidem as capacidades de um sujeito do conhecimento. Serres vai tratar de uma retroação do mundo, ou objeto sobre o sujeito, como resultado dessas ações de subordinação e 
poder desmedido e irresponsável do sujeito sobre seu mundo. Com os consequentes problemas ambientais que surgiram e até mesmo a possibilidade de extinção dos seres humanos, o sujeito tornou-se, então, objeto de uma retroação do mundo sobre ele. Para tanto, $O$ contrato natural (1991) surge como forma de propor a consideração do mundo como um sujeito de direitos.

Essa questão da mútua implicação ora sujeito, ora objeto nos ajuda, também, a seu tempo, a pensar as contribuições de Serres para uma filosofia da educação, impactando diretamente sobre as perspectivas e abordagens dos ditos fundamentos da educação. Como considerarmos os fundamentos da educação a partir de um pensamento que nos faz repensar as posições sujeito/objeto? No que isso implica para a educação de nossos tempos? São algumas das questões que buscamos levantar neste trabalho, ao trazermos a filosofia de Serres como aquela que busca a pluralidade de correspondências, por meio de estabelecimentos que levam a harmonias temporárias e abertas. Essas correspondências, por sua vez, nos ajudam a traçar as implicações para uma filosofia da educação, pensada a partir dessa teoria das multiplicidades, que se constitui em Serres como relação na diferença.

Mais precisamente, na entrevista que realizamos, Serres nos ajuda a compreender essa passagem que aconteceu no seu pensamento entre a inspiração do pluralismo leibniziano e a constituição de seu próprio pluralismo, o qual engendra a relação na diferença. Em que momento a inspiração de ordem leibniziana bifurca? Quando e em que sentido acontece a passagem? Segundo Serres, essa passagem aconteceu em razão das ciências: "o pluralismo, é verdadeiramente hoje uma filosofia que é aquela de todas as ciências". O pluralismo do Serres leibniziano bifurcou, portanto, na diversidade das ciências e dos saberes que elas vinculam hoje e para os quais ele busca uma teoria geral das correspondências ou a comunicação entre esses saberes a partir da constituição de harmonias temporárias sempre abertas. É sobre essa questão e suas consequentes implicações para o pensamento em educação que trataremos daqui por diante. 


\section{2 - Desafios contemporâneos da educação}

Na entrevista realizada com Serres em 2014, conversamos sobre educação, contemporaneidade e multiplicidade. Indagado, incialmente, sobre o que é educação, Serres afirma que, dentre as muitas respostas que a questão pode ter, ele prefere começar pela diferença que há em língua francesa, assim como há em português, entre educar e instruir. Nesse sentido, Serres explica porque estaria ele interessado nesse problema sobre instrução e educação, resposta que, ao mesmo tempo, nos faz compreender a passagem que acontece entre Filosofia mestiça e Polegarzinha. Essas obras marcam as diretrizes do seu pensamento em educação. Serres diz que se interessa pela diferença que existe entre educar e instruir, porque uma certa cultura estava se modificando no espaço de tempo (1993-2013) que separa a composição dessas duas obras.

Para Serres, portanto, a fim de que possamos pensar a educação, é preciso termos clareza, primeiro, sobre esses dois movimentos complementares que constituem a formação: educar e instruir. Movimentos complementares, visto que, conforme o filósofo, não podemos pensar uma educação sem instrução. Toda educação passa, a princípio, por uma instrução, pela transmissão de uma informação ou de um saber. E de forma semelhante, não nos interessa um processo de instrução que não leve à educação, que não leve a contribuir para experiências que impactem na formação da pessoa, embora existam processos assim. Nesse sentido, no caso específico dos tempos atuais, Serres afirma que o que modificou na educação da Polegarzinha, a garota que hoje porta o seu celular com acesso direto à internet, é que houve uma mudança no acesso à informação. $\mathrm{O}$ acesso à informação tende a ser atualmente fácil, imediato e disponível, de tal forma que isso inevitavelmente deverá impactar nas instituições que antes tinham o privilégio de conter exclusivamente o conhecimento e a informação. Nesse caso, em especial, as escolas, as universidades e os centros de pesquisas. E em que sentido precisamente essa mudança afetou o jogo do ensino? 
Logo, o que muda no jogo do ensino hoje não é só o acesso à informação, mas, mais do que isso, é a pessoa que se modifica ao estar neste mundo de acessibilidade total à informação. A Polegarzinha, assim, com seu dedo frenético e constantemente sobre o celular, é a singularidade, o personagem/mônada que retrata a totalidade desta nova população de jovens que é engendrada hoje pelo avanço e pela predominância das tecnologias de informação e comunicação em todos os espaços. Circunstância, por outro lado, bem diferente, daqueles que, por não terem sido engendrados por elas, utilizam essas tecnologias apenas como ferramentas. É preciso ter atenção para essa diferença, além de boa vontade para ver nela algo de novo a ser compreendido e acolhido, em especial, nas instâncias de formação, diretamente impactadas, quer queiram ou não, por essa mudança no jogo do ensino. Por outro lado, não se pode deixar de destacar também, sobretudo na nossa sociedade marcada ainda por grandes desigualdades sociais, a existência de um número considerável de "polegarzinhas amputadas", que engendradas igualmente pelo avanço e predominância das tecnologias, têm, entretanto, o acesso a esses suportes e suas potencialidades inviabilizado de forma cruel e excludente. Há, portanto, não somente a mudança no jogo do ensino, como também uma velha mazela social de exclusão digital que não deixa de vir atrelada a essas modificações e que na realidade da educação brasileira é algo que precisa ser considerado em princípio. Se o jogo do ensino mudou pela incidência das novas tecnologias, como fica ainda a relação com o ensinar/aprender dessas polegarzinhas amputadas? Essa é uma outra questão que o cenário das mudanças no jogo do ensino nos suscita pensar.

Mas a reflexão sobre a educação não para por aqui. Além da diferença entre instruir e educar, Serres nos fala ainda de outro elemento que complementa a questão anterior. No final das contas, educar, além de ser mais do que instruir, é, sobretudo, promover o êxtase. O que essa outra resposta traz de complemento à anterior? Para Serres, educar é um movimento que não abdica da instrução, mas ele é mais do que instruir, ele consiste em propiciar experiências que formem a pessoa. E para propiciar 
essa experiência, é fundamental que aquela informação, aquela instrução obtida seja, por fim, compreendida. Compreendida de tal forma que ela produza o êxtase de adentrar um outro mundo. Ao promover esse êxtase de adentrar um novo mundo, algo de formação acontece na pessoa, visto que ela já não é mais a mesma pessoa de antes. Ela conhece, ela experimenta uma outra realidade e sai dali transformada. Por conseguinte, nesse movimento de instrução-compreensão-formação, qual elemento intervém que ainda não foi considerado? $\mathrm{O}$ professor. $\mathrm{O}$ educador. Ou seja, aquele que vai conduzir o aluno da instrução - obtida hoje muito rapidamente pelos novos suportes - à compreensão desse volume díspar e muitas vezes contraditório de informações que os jovens têm a sua disposição. Nesse caminho da instrução à compreensão, da instrução ao êxtase, pela intermediação do professor, forma-se, pois, algo no aprendiz. É interessante contrapor aqui, nesse sentido, os discursos alarmistas que vêm nas mudanças promovidas sobre a população Polegarzinha pelas novas tecnologias de informação e comunicação, o fim dos tempos. O fim do conhecimento verdadeiro, hermético, estruturado, unicamente válido e da hegemonia das instituições de ensino e do professor como o senhor do saber, dizendo ver surgir, em lugar disso, um nada, um vale tudo, uma degeneração completa do saber e do ensino, a qual é preciso temer. Contrapomos a esses discursos as reflexões de Serres, que, da mesma forma, vê, também, implodir a instituída relação do aluno com as instâncias de concentração do saber e, sobretudo, com o professor compreendido como aquele que detém a informação, única e verdadeira. Mas no lugar do nada a substituir essas relações instituídas e hierarquizadas de poder, no lugar dessa degeneração que se considera temerosa, Serres vê surgir uma relação mais igualitária e de desconcentração do saber, a qual, longe de eliminar o lugar do educador, o torna cada vez mais necessário, mas não em razão de uma relação de quem detém o conhecimento, mas como aquele que é capaz de fazer o aluno passar da mera instrução, a experiências de formação. Isto é, como aquele que o faz adentrar um novo mundo. Dessa maneira, mais no 
sentido do pedagogo do que do professor, compreendido no seu sentido clássico, como a pessoa que conduzia a criança da casa até a escola.

Certamente, essa visão do professor não como o detentor do saber, mas como aquele que conduz ao conhecimento, a princípio, nada tem de muita novidade no campo dos saberes da educação. De certa forma, esse campo já está saturado de perspectivas como esta: que é preciso não só instruir, mas formar a pessoa em geral; que o professor não detém o saber e que deve, portanto, conduzir o aluno a construir por si mesmo o conhecimento etc. As perspectivas psicodesenvolvimentistas e pragmáticas da educação muito já falaram sobre isso. Contudo, apesar dessa aparência de déjà-vu, há algumas particularidades na proposta de Serres que devem ser consideradas.

Para compreendermos a particularidade da proposta, sem esbarrarmos em discursos já desgastados, é necessário retornar a diretriz principal do pensamento de Michel Serres sobre educação, Filosofia mestiça (1993), a qual, após mais de 20 anos da publicação, continua a ser, segundo Serres, a sua obra mais importante sobre as questões educacionais. A concepção da educação como mestiçagem que a obra propõe, implicada na passagem necessária e muito relevante entre as ciências exatas e as ciências humanas, traz em germe as particularidades que diferenciam a proposta de Serres e sobre as quais já trabalhamos mais precisamente em outros textos ${ }^{2}$. Esses diferenciais ou particularidades se assentam, precisamente, na concepção de que a educação acontece no encontro com o diferente. Um encontro que não somente acontece, mas que deixa marcas, resultando numa transformação do indivíduo que aprende. Nessa transformação, ele já não é mais o que era antes e nem tão menos ele se transforma no outro que ele encontrou. $\mathrm{Na}$ verdade, ele se torna um terceiro, um misto entre o que ele era e o outro que ele encontrou. Dessa forma, a educação aconteceria somente em razão desse encontro com o diferente que me transforma. E para encontrá-lo, é preciso que eu me desloque, que eu saia do já estabelecido e parta em direção ao

${ }^{2}$ Confira, sobretudo, Oliveira e Santos (2007).

Filosofia e Educação [RFE] - Volume 9, Número 2 - Campinas, SP Junho-Setembro de 2017 - ISSN 1984-9605 - p. 98-124 
diferente. Portanto, a educação se dá no deslocamento, e esse deslocamento nunca acontece sem uma força propulsora que nos tire da inércia para a qual tendemos naturalmente. Essa força propulsora é o educador, que pode ser o professor ou qualquer outra coisa que me tire da inércia, que faça gerir em mim o desconforto, que me tire de minhas certezas. É nesse sentido, portanto, que educar é levar o aluno ao contato com o diferente por meio da compreensão de uma determinada instrução ou informação que seja forte o suficiente, intensa o suficiente para me tirar do meu já estabelecido. Assim, eu me formo ou eu me transformo.

Observemos, então, as diferenças da proposta de Serres em relação a alguns discursos predominantes em educação. Não se trata, especificamente, de tirarmos o lugar do professor em relação ao conhecimento, nem desses discursos muitas vezes vazios e genéricos de que é necessário formar a pessoa em geral, e não só instruí-la. Trata-se, sim, de considerar a educação no espaço da relação com a diferença. Nessa consideração, o professor como aquele que conduz e a educação como transformação da pessoa são apenas consequências de uma proposta primeira que se sobreleva: $a$ educação na diferença e nas multiplicidades. Essa inversão do foco muda completamente o jogo da proposta ao retirá-la dos discursos vazios e genéricos que acabam sem sentido para os sujeitos da educação e o coloca, por sua vez, como resultado de uma concepção e uma ação mais concreta: educar promovendo deslocamentos pelo contato com o diferente, tirando das estabilidades do já conhecido, isso podendo acontecer tanto no âmbito da instrução, da relação com um novo saber, quanto no âmbito de outras experiências de contato com o mundo e com os outros. E ao professor cabe saber que o que modificou o seu aluno, que o que abriu esse novo mundo a ele, no qual ele se transforma, não foi precisamente o que ele, professor, sabe, mas foi o impacto do que ele sabe sobre esse aluno e, sobretudo, a forma e as circunstâncias com que esse aluno se encontrou com esse saber. E, por fim, como esse saber, essa informação, se mesclou com tudo aquilo que ele já trazia em si de experiências e de formação. Um conjunto complexo de relações em que interferem não somente o saber canonizado e 
a relação do sujeito do ensino com o saber, mas também as circunstâncias e condições daquele que o recebe e como recebe essa informação, tudo isso resultando em experiências de formação, que, pela diversidade em que se dão e pela complexidade das relações, serão sempre singulares e únicas para cada um. Logo, qual não é a pertinência de uma teoria das multiplicidades, para um pensamento em educação? Como não ver, por meio dela, uma perspectiva capaz de nos tirar da concepção generalizante e unificadora, incapaz de suportar essa variedade contínua própria do jogo de experiências de formação ou, quiçá, de deformação?

As mudanças que agem sobre a educação da Polegarzinha modificam, mais precisamente, as condições e circunstâncias que interferem no jogo de experiências de formação ou no jogo em que a nova população será conduzida ao encontro com o diferente. Isso porque a Polegarzinha vive hoje no mundo de acesso imediato à informação e comunicação, e isso muda, consequentemente, a sua relação com o educador que a conduzirá e com as instituições de ensino que já não são mais os únicos espaços portadores de informação e conhecimento. E em que sentido, objetivamente, acontecem essas transformações? Para Serres, elas impactam, preponderantemente, na relação que a Polegarzinha tem com as instâncias espaço e tempo.

Um novo espaço de proximidade que muda a relação de vizinhança, um novo suporte de informação que altera as condições de saber no nosso tempo, assim como alterou ao longo da história o surgimento de outros suportes de informação. É por meio dessas análises que Serres compreende a população Polegarzinha e é por meio delas que ele busca inventar um pensamento que seja capaz de considerar os sentidos possíveis dessa nova condição. Nada de discursos reacionários que buscam condenar essas mudanças, nada de rejeição das novas condições e de defesa da manutenção do já instituído. É preciso acompanharmos os movimentos de ação e retroação da história, mesmo que não se concorde com eles, ou não se compreendam, a princípio, os rumos que as coisas tomaram. O fato é que elas estão aí. E o que se faz com elas? Essa é a tarefa do filósofo, procurar 
pensar e dar a perceber as novas condições de seu tempo. Interessante notarmos que, no caso desses discursos reacionários contra as mudanças nos suportes de informação, Serres nos mostra como eles são os mesmos ao longo da história. Na passagem do oral ao escrito, do escrito ao impresso e do impresso ao digital, permanecem, curiosamente, os discursos que conclamam os riscos da banalidade do conhecimento ao democratizarmos o acesso. Uma vez que escrevemos o que antes apenas alguns diziam, agora todos e qualquer um poderão dizer, Isso é o fim da garantia de veracidade, já que se imprimimos em grande quantidade o que antes só havia escrito para alguns e por alguns. Isso é o fim, é a banalidade do conhecimento, já que todos e qualquer um poderão publicar o que escrevem, uma vez que se chegou do impresso ao digital e se se livrou do peso material dos livros, podendo contê-los todos juntos e ao mesmo tempo em um pequeno suporte. Isso é o fim, a banalidade do conhecimento e um vale-tudo da informação, já que todos e qualquer um não possuem os crivos suficientes para selecionar o que é válido e o que não é válido no conhecimento. Sempre o mesmo discurso reacionário que busca manter o privilégio de alguns no acesso ao conhecimento e a relação hierarquizada que esse privilégio, consequentemente, engendra.

Não que todas essas modificações não tenham trazido também algum tipo de transtorno ou efeitos colaterais, os quais é necessário acertar, pontuar, equilibrar. Há, sim, sempre um lado pernicioso nas novidades. Tudo não é só potencialidades e progresso, uma vez que a realidade é sempre uma mistura, um complexo de diferentes faces. É preciso, no entanto, olhar para as potencialidades e fazê-las proliferar, desenvolvê-las a tal ponto de sufocar as suas possíveis faces perniciosas. Tudo depende do enfoque que damos e qual dimensão queremos fazer vingar. Com o digital, não é diferente. Há consequências negativas várias dessa facilidade de acesso aos suportes de comunicação e informação para a educação e a convivência na diferença. Há consequências negativas também se considerada a realidade de exclusão digital que uma grande parcela da sociedade vive hoje. Vemos esses problemas surgindo e se agravando a cada 
dia. Mas há também muitas potencialidades e é para elas que Serres nos convida a olhar.

Notemos, contudo, que as consequências ou potencialidades que Serres extrai das mudanças que condicionam uma nova proximidade de vizinhança da mesma forma que são interessantes, sobretudo, por nos levarem a pensar as possibilidades das mudanças que acontecem na contemporaneidade, também nos levam a desconfiar de um certo otimismo exagerado que transparece delas. Um otimismo que pode beirar a ingenuidade se considerarmos o uso que tem sido feito, por exemplo, das tecnologias de informação e comunicação para recrutar combatentes em diversos lugares que estejam dispostos a morrer por um ideal de uma dita "cultura ou religião", para tanto, promovendo a guerra e o terror contra as outras culturas e as pessoas de outras nacionalidades. Por conseguinte, é fato que as novas tecnologias aproximaram muito as pessoas e as culturas, promovendo essa sensação de comunidade global, mas é fato também que existem outros usos desses recursos para fins completamente inversos desses. Persistem a complexidade, a mistura da realidade, entre potencialidades e degenerações. Por que, então, Serres ressalta tanto as potencialidades? Por que esse otimismo, aparentemente, exagerado? Perguntamos a ele se seria possível ver nessa postura não um otimismo, mas sim uma filosofia da afirmação como proposta por Nietzsche. Sua resposta nos diz: otimista sim, pelas condições de seu tempo; afirmativo sim, pela forma como se coloca diante dessas condições e, somado a isso, uma alegria clara e declarada pela possibilidade de vida, Serres compõe, assim, sua filosofia otimista/afirmativa em prol da vida. E para aqueles que o estudam e que buscam as implicações de seu pensamento para seus objetos de pesquisa, fica a marca em seus trabalhos dessa postura e dessa forma de se colocar diante da vida e do mundo.

Vejamos, em nosso caso, como essa postura se distende, além do que já tratamos até aqui, na questão específica da relação com o conhecimento em face da diferença e da multiplicidade. Ponto esse, a partir do qual chegaremos à questão, enfim, que nos move: como pensar uma filosofia da 
educação na perspectiva de um pensamento das multiplicidades como teoria da comunicação? E de que forma esse projeto de filosofia da educação pode contribuir para o estabelecimento de um ' a'fundamento da educação?

No que se refere ao conhecimento em face da diferença e das multiplicidades, segundo Serres, dois pontos relevantes, também abordados na entrevista que realizamos, se destacam: a Passagem do Noroeste e a formação curricular.

O conceito Passagem do Noroeste, conforme já dissemos neste trabalho, sempre foi recorrente na filosofia de Serres, como forma de aludir a difícil e necessária relação entre as ciências e as culturas, relação essa que deveria contar como uma das questões mais importantes ou um dos objetivos principais dos projetos em educação. Considerando esse conceito e as mudanças na educação da Polegarzinha, indagamos a Serres se, permeada por essas modificações, a difícil Passagem do Noroeste poderia, consequentemente, se tonar menos tortuosa. Observamos, pela resposta de Serres, que, quanto à relação entre os diferentes saberes, que sempre foi um problema importante para sua filosofia, considerada sempre pelos seus muitos obstáculos e pelo grande abismo que a inviabiliza, a sua filosofia encontrou novos encaminhamentos a partir da ideia de Grande Narrativa e a partir também das novas condições na educação da Polegarzinha. No primeiro encaminhamento, a passagem que Serres entrevê se dá por meio dos avanços da ciência na datação da vida. É por meio desses avanços que ele consegue unir os pontos divergentes e constituir essa longa narrativa sobre o homem, a vida e o planeta. Já no segundo encaminhamento, trata-se do acesso a essas informações, a esses avanços da ciência, bem como a todos os outros tipos de informações, os quais aproximam a nova população da diversidade do conhecimento. $\mathrm{O}$ impedimento espacial e material, que antes limitava em muito o contato e a aproximação com esses saberes, foi potencialmente eliminado pelas novas tecnologias. A aproximação, ou o acesso aos diferentes saberes, agora é realidade consolidada. E, por sua vez, subsiste ainda a presença do educador nesse novo cenário. Mais precisamente, essa presença se dá no sentido da compreensão, como já 
dissemos, mas também e, sobretudo, em um outro sentido muito significativo para a constituição do processo educativo e sobre o qual trataremos em sequência.

Esse outro sentido está implicado na reflexão que Serres faz sobre como surge o novo no âmbito mesmo da formação disciplinar, esta, ao seu tempo, permeada pela noção de rigor. Isso porque, ao propor a reflexão sobre a relação entre os diferentes saberes, a filosofia de Serres não só aproxima os diferentes, como abre a possiblidade do novo que surge a partir dessa relação, mantendo, assim, o movimento de variação contínua, característico de sua teoria das multiplicidades, conforme vimos tratando neste trabalho. Mais precisamente, a questão que se coloca é: como em uma relação entre diferentes domínios disciplinares é possível passar do rigor conceitual que as constitui à formação de um terceiro, sem, com isso, se perder a precisão disciplinar? Como surge o novo nessa relação e o que acontece com a precisão conceitual e disciplinar que havia em cada domínio antes dessa relação? Uma questão muito específica hoje nas reflexões que permeiam o campo educacional sobre inter/multi/transdisciplinaridade. Questão que se caracteriza por afirmar uma dicotomia: ou se faz a passagem entre os saberes e se perde a precisão, construindo uma abordagem negativamente superficial dos conhecimentos referidos; ou se mantém nessa precisão e se mergulha cada vez mais nos domínios especializados, conhecendo muito bem uma coisa e ignorando todo o resto. Como superar esse aparente dualismo? Para Serres, essa é uma questão sobre a qual ele refletiu muito e talvez ainda não tenha encontrado uma boa resposta.

Por conseguinte, quanto à relação com o conhecimento, a filosofia de Serres, da mesma forma que propõe a busca da aproximação entre os diferentes saberes, por uma proposta de formação enciclopédica, permeada pela concepção de uma Grande Narrativa, propõe, por sua vez, outro movimento tão importante quanto essa unificação a princípio, movimento que consiste na bifurcação, na mudança de sentido, assim como acontece com o clinâmen dos átomos. É preciso conhecer e conhecer bem, conhecer com rigor; é necessário promover passagens e aproximações, buscando uma 
formação cada vez mais enciclopédica. Mas, depois, a ação principal é bifurcar, mudar de sentido para criar o novo. É dessa forma que não se cessa o movimento. Visto que a realidade é múltipla e plural, é fundamental sempre partir em busca de novos encontros, livrando-se da bagagem que se carrega, afrouxando as fronteiras e o rigor, despindo-se de suas certezas para um real encontro com a alteridade. Este é o movimento principal na filosofia de Serres: promover unificações temporárias para, em seguida, bifurcar. Buscam-se as unificações, as composições temporárias, mas para, tão logo, despir-se de tudo isso e seguir na mudança de sentido pela bifurcação. Para tanto, ele elege um novo personagem/mônada como singularidade que encarna o sentido da mudança de sentido. Esse é le gaucher boiteux, ou o Canhoto coxo, apresentado por Serres em sua recente obra (2015). Personagem que nos ajudará a compreender, por fim, o lugar da bifurcação neste processo que vimos analisando, refletindo igualmente sobre qual o seu lugar nas contribuições de um pensamento das multiplicidades como teoria da comunicação para um 'a'fundamento da educação.

As reflexões de Serres no âmbito da educação nos convidam, pois, a pensar, tanto a educação como relação na diferença, quanto a avaliar de que maneira as transformações que os novos suportes de informação e comunicação podem afetar uma educação, assim, compreendida. Para potencializar ou viabilizar uma educação na diferença, é preciso promover deslocamentos, liberar as condições de encontro com a alteridade, as quais podem se materializar nos diferentes saberes e conhecimentos, bem como nas diversidades de paisagens, culturas e mundos. Na convergência disso, uma educação capaz de promover esses encontros com o diferente está hoje, potencialmente, muito mais ao nosso alcance do que já esteve em outros tempos, visto que as novas tecnologias de informação e comunicação lançam as condições desses encontros por via de outras possibilidades de vizinhança e pela democratização das informações com os novos suportes. Ou seja, pessoas, mundos, culturas e conhecimentos podem estar hoje incomensuravelmente abertos a nós pelos novos suportes. Todavia, para que possamos fazer vingar essa possibilidade, para que possamos fazer vir à 
tona esse lado de convergência das novas tecnologias no sentido de uma educação na diferença, é fundamental uma transformação nas perspectivas de abordagem da educação. Do contrário, continuaremos a ver retrocessos, banalizações e fins dos tempos, onde podemos ver multiplicidades, vizinhanças, comunidade global, dissipação das concentrações de saber e relação na diferença. É para essa transformação que este trabalho busca contribuir ao tratar de uma filosofia da educação implicada pelas concepções de um pensamento das multiplicidades como teoria da comunicação.

Então, que uma teoria das multiplicidades e o pensamento da diferença em princípio possam implodir com as ideias estabelecidas, instituídas e canonizadas de uma realidade de concentração do saber em um ponto fixo e de relações hierarquizadas, e lancem, assim, as condições para fazer vingar as potencialidades entrevistas nas condições da educação na contemporaneidade. E que isso possa acontecer, viabilizado por um projeto de filosofia da educação, enquanto convergência de uma teoria das correspondências para um 'a'fundamento da educação.

\section{Referências}

DELEUZE, Gilles. A dobra: Leibniz e o barroco. Trad. Luiz B. L. Orlandi. Campinas: Papirus, 1991.

OLIVEIRA, Wanderley Cardoso de; SANTOS, Maria Emanuela Esteves dos. A educação como mestiçagem em Michel Serres. In: OLIVEIRA, Wanderley Cardoso de; PEREIRA, Lúcia Helena Pena (Org.). Práticas educativas: discurso e produção de saberes. Rio de Janeiro: E-papers, 2007, p.119-145.

SANTOS, Maria Emanuela Esteves dos. Educação e contemporaneidade em Michel Serres. Pro-Posições, v.26, n.1(76), p.239-257. 2015.

SERRES, Michel. Le système de Leibniz et ses modèles mathématiques. Paris: P.U.F, 1968.

O contrato natural. Trad. Beatriz Sidoux. Rio de Janeiro: Nova Fronteira, 1991.

Filosofia e Educação [RFE] - Volume 9, Número 2 - Campinas, SP Junho-Setembro de 2017 - ISSN 1984-9605 - p. 98-124 
Filosofia mestiça. Rio de Janeiro: Nova Fronteira, 1993.

. Polegarzinha. Rio de Janeiro: Bertrand Brasil, 2013.

. Le gaucher boiteux: puissance de la pensée. Paris: Le Pommier, 2015. 